\title{
Capítulo 4: Los consejos en los foros digitales
}

\author{
Susana A. Eisenchlas
}

\begin{abstract}
Hola. Tengo una cita la próxima semana con un chico q me gusta, y q conozco de internet; nos conocemos de poqito, pero estudia en mi universidad. Me gusta, pero no sé si yo a él. Me ha propuesto quedar, y he aceptado; pero no sé si dar un beso o no en esa primera cita (simplemente será conocernos y tomar café). Q opinan ustedes? Creen q le intereso? Debería besar ya o dejarlo con ganas para una próxima cita??? (Yahoo Respuestas, sin fecha)
\end{abstract}

(a): Hazlo como tu creas, si lo haces por lo que te aconsejen lo estarás engañando y no sabrá como eres realmente. Depende de como sea el, puede ser un factor importante. Y no vas a contratar un detective para saber cómo es $y$ cómo se lo va a tomar y hacer lo que sea mejor, ¿verdad?.

Itxaso: si,se debe besar,pero no lo hagas mucho,solo un beso,vaya a ser que piense que quieres ir a mas, ahora los chicos son asi,como te pongas cariñosa en la primera cita...chungo chungo, a mi me ha pasado con todos los novios que tuve que por darles 4 besos en la boca enpezaron a intentar meterme mano isolo por 4 besos!

Nano: lo dificil no es el primer beso sino el ultimo.

has lo que tu sientas y quieras

Tracy: si pero hazte la dificil y asi la cita sera muy interesante

\subsection{Introducción}

Los consejos que presentamos arriba y que discutiremos en el resto del capítulo ilustran una de las manifestaciones más curiosas del uso de Internet: la proliferación de consejos entre extraños en los foros digitales. Con el mundo al alcance de la yema de los dedos, un número creciente de personas solicita, obtiene y posiblemente actúa, en función de consejos dispensados por interlocutores desconocidos, sin tener en cuenta los riesgos potenciales implicados en esta práctica (transmisión de información errónea, uso de lenguaje o contenido abusivo, intentos de adultos predadores de tener acceso a menores, etc.). Esta tendencia se puede encontrar en una amplia gama de áreas, como los viajes y restaurantes (Tripadvisor), la salud y la sexualidad (Yahoo Respuestas) y las relaciones sentimentales (Mundo Psicólogo). Dada su creciente popularidad y facilidad de acceso, esta extendida práctica discursiva mediada por ordenador puede usarse para explorar normas y expectativas sociales a través del examen de interacciones auténticas en línea.

Dar y pedir consejos, tanto cara a cara como en línea, es una actividad cotidiana, aparentemente simple, que ocurre entre amigos, familiares, profesionales y, cada vez más, entre extraños. Ya sea solicitado o no, el consejo es un acto de habla exhortativo (Searle, 1976) en el que un participante intenta influir o guiar el comportamiento de otro. Los consejos difieren de otros actos de habla exhortativos, tales como las órdenes y las peticiones, en que el consejero espera que su consejo beneficie al destinatario. Por lo tanto, es posible considerar el consejo como una directiva no impositiva (Haverkate, 1994). 
El consejo posiciona a los participantes de forma asimétrica en términos de estatus y poder, ya que el que aconseja se proyecta como más experto que el receptor del consejo. Muchas investigaciones se han centrado en esta asimetría, en su potencial para amenazar la imagen social del receptor del consejo (v. Locher, 2006), y en las estrategias discursivas que utilizan los consejeros para reducir esta amenaza y hacer que sus consejos sean aceptados/aceptables. Por otra parte, se ha prestado menos atención al asesoramiento entre pares, y a las estrategias empleadas cuando no son expertos los que aconsejan, y donde los participantes están en igualdad de condiciones.

Al igual que con cualquier acto de habla, diversos factores contextuales (el tipo de consejo buscado, la relación consejero-receptor, la experiencia del consejero, la edad y género de los participantes) desempeñan un papel importante para explicar por qué las personas expresan estos actos de habla tal como lo hacen. Pese a la importancia del tema, solo recientemente se han comenzado a estudiar otros factores, tales como el medio de comunicación y su posible influencia en la realización de este acto de habla. Si bien la mayoría de los estudios de actos de habla se han centrado en interacciones orales, la informatización de la cultura ha dado lugar a intercambios cada vez más frecuentes en el ciberespacio, un medio que los investigadores creen que está desarrollando sus propias normas de comunicación (Yus, 2010). La realización de consejos entre pares en los medios digitales es el objetivo del presente capítulo.

\subsection{Enfoque y objetivos}

En este capítulo ilustraremos cómo se puede abordar el análisis de los consejos en foros digitales a través de un pequeño corpus de consejos obtenido de distintos sitios web de Argentina. Seguiremos la propuesta del análisis del discurso mediado por ordenador (Herring y Androutsopoulos, 2015), un enfoque basado en la observación empírica y textual, y adecuado para explorar sistemáticamente la formulación de consejos en línea, así como las normas o expectativas sociales que informan de su uso.

La investigación en Internet tiene muchas ventajas: 1) permite el acceso directo a datos de interacciones auténticas sin que el investigador pueda influir en los resultados o en los procesos de recopilación de datos; 2) dado que los datos, aunque escritos, también exhiben características del lenguaje hablado (Yus, 2010: 200), es posible acceder de forma directa a lo que los hablantes realmente "dicen" en lugar de usar, por ejemplo, datos generados por medio de cuestionarios u otras herramientas que pueden dar acceso a percepciones de uso pero no a habla natural y espontánea (v. cap. 20); y 3) es posible obtener rápidamente una gran cantidad de datos que pueden usarse para crear un corpus, sin tener que invertir el tiempo y esfuerzo requeridos en la transcripción de interacciones orales.

\subsection{Análisis de los consejos}

Los datos que analizaremos en este capítulo son respuestas a pedidos de consejos sentimentales en línea, solicitados por jóvenes de ambos sexos, sobre cómo romper con un novio / novia sin herir sus sentimientos. El corpus incluye 232 respuestas producidas por 185 contribuyentes. Los consejos fueron clasificados como tales si los consejeros utilizaron consejos con: 1) un performativo explícito (Te aconsejo que hables con ella sobre tu relación y lo que no está funcionando); 2) imperativos (Dale tiempo), o subjuntivos en oraciones negativas (No te engañes más a ti mismo, Brad Pitt); 3) verbos modales de obligación (Tienes que estar seguro de eso); 4) juicios de valor o expresiones impersonales (Es más fácil dejar una relación lo antes posible); o si la respuesta consistía en una experiencia personal que ofrecía sugerencias implícitas pero inequívocas. Todos los textos que presentamos a continuación fueron copiados tal como los consejeros los formularon y no han sido editados, de ahí que puedan contener 
errores gramaticales, ortográficos, etc. Como se verá en los ejemplos de la sección 3.2, las respuestas, de forma general, incluyen más de un consejo por entrada.

\subsubsection{Elementos de los consejos}

El primer paso en el análisis consiste en distinguir el consejo propiamente dicho de las estrategias discursivas que lo acompañan. El tipo de consejo más directo, por medio de un imperativo, se puede ver en (1) y (2).

\section{(1) échate la culpa [CONSEJO]}

\section{(2) loco ponete las pilas [CONSEJO] y dejala! [CONSEJO]}

Sin embargo, como se ha indicado anteriormente, los consejos generalmente se encuentran enmarcados en otras estrategias discursivas que tienen como finalidad principal hacerlos más aceptables y convincentes. Las estrategias más frecuentemente usadas son evaluaciones y elaboraciones. Siguiendo a Locher (2006), consideramos evaluación como "un pasaje en el que se menciona y analiza la situación particular de quien pide consejos" (2006: 63; traducción propia), mientras que la elaboración es considerada como una explicación de un consejo recién dado.

Los ejemplos (3) y (4) ilustran estas estrategias, indicando la estrategia discursiva relevante entre corchetes.

(3) Y mira, es jodido. Vos seguramente no queres lastimarlo, pero por hacer eso, te estas lastimando vos [EVALUACIÓN]. Tenes que pensar un poco mas en vos y cortar por lo sano [CONSEJO].

(4) Simplemente hablarle con sinceridad, con la misma confianza de siempre, (quiero creer que se tenían confianza) [CONSEJO] la lastimaras mas si solo estas con ella por lastima o compromiso.... [ELABORACIÓN]

Varias estrategias presentes en el corpus ilustran la categoría que Pudlinski (2005) denomina expresión de empatía. Añaden igualmente sub-categorías que incluyen reacciones emotivas, expresar los propios sentimientos ante el problema de otro, informar sobre la reacción propia, comunicar una experiencia similar, mencionar resultados positivos que pueden esperarse si el receptor implementa el consejo ofrecido. La mención de experiencias compartidas, como en (5), funciona como un medio para establecer solidaridad o demostrar empatía con el solicitante de consejos. Discutir experiencias propias (6) puede considerarse como una forma de establecer la autoridad o idoneidad del consejero para ofrecer consejos. La mención de resultados positivos (7) también sirve como un medio de brindar apoyo al solicitante de consejos.

(5) amigo a mi me pasa lo mismo,la verdad..mira habla con ella,que sea una conversacion seria,dile que es lo que tu quieres para tu futuro y dile que es lo que con el tiempo ya no te gusta de ella..si no colocan las cosas claras de una ves..solo estaras jugando unh juego sin sentido

(6) tambien pase por esto.animo suerte a quien se encuentre en esta situacion. aqui he leido comentarios que pueden ser de mucha ayuda. lo mas importante: haz todo lo que este en tu mano para ser feliz. lo demas es secundario. morir te vas a morir igual, asi que mientras estas aqui, lucha por tu felicidad y la de nadie mas. 
(7) me paso lo mismo q a vos 3 años...[EXPERIENCIA COMPARTIDA] hace 2 semanas me pelee con mi novia y creo q soy el tipo mas feliz del mundo! unos dias anduve re mal...pero busque reparo en mis amigos! [EXPERIENCIA PERSONAL] y ahora nose...soy feliz! jajaa ya estuve con un par de minas y todos...dejala de una! aprovecha q la vida es una sola! saludos!!

Otras estrategias afectivas incluyen el uso de vocativos como loco (2) y amigo (5) (v. Capítulo 7), saludos y despedidas (7), ofertas de ayuda adicional y expresiones alentadoras (8), y empleo de emojis, en especial smileys (7). El ejemplo (8) ilustra varias de estas categorías y otras:

(8) ??? como le fue compadrito [VOCATIVO][PREGUNTA]

arreglo su problema [PREGUNTA] yo aun estoy igual que tu

no logro hacer nada para que ella cambie [EXPERIENCIA COMÚN]

te dejo mi correo para que podamos hablar [OFERTA DE AYUDA]

si alguien mas quiere agregarme seria genial

esto lo debemos arreglar [ALIENTO]

saludos cordiales. [SALUDOS]

Manifestaciones adicionales de emoción incluyen el uso del humor (9), y la presencia de abuso (flaming) (10). El humor se utiliza principalmente como estrategia de mitigación, y está indicado, por lo general, por expresiones de risa basadas en texto (jajaja o jeje), una broma (9) o emoticonos (7). Las respuestas fueron consideradas abusivas si contenían una evaluación insultante o despectiva de los solicitantes de consejos o sus parejas. Los casos de abuso no fueron frecuentes, pero la presencia de abuso es consistente con resultados de otros estudios (v. Eisenchlas, 2012) que sugieren que el anonimato del medio alienta estas manifestaciones.

(9) presentamela a mi y en menos de una semana te va a dejar

(10) Sos un mierda chavon le cagaste la vida a la piba, si quieren joder xq no lo dicen de una listo, no esperar a q te ilusiones para despues darte una patada en el ort....

Actividad 1: Elementos de los consejos. Examina las siguientes respuestas y determina en cada caso cuál es el consejo y cuáles son las estrategias discursivas que lo enmarcan. Recuerda que una respuesta puede incluir más de un consejo, y que el orden de las estrategias es variable.

a. No hay forma de cortar a alguien sin lastimarla y menos si te quiere lo mas conveniente y si es que alguna ves la quisiste dicelo de frente y con la frente en alto y hasle ver que lo haces por los 2 no solo por ella por que tu felicidad tambien esta en juego, solo una cosa si la vas a dejar respeta eso y no despues hagas tus niñerias que siempre si la quieres por que ahi si la lastimarias mas y tu igual camarada ese es mi consejo ojala y te sirva.

b. Ok, quizas tu problema es que quieres dejarla pero sin lastimarla, puede ser una obviedad que le duela mucho al decirle que ya no sientes nada por ella y que queres cortar la relacion, pero a veces hay que ser sincero y hacerle caso a tu corazón, esto te servirá para tener mas seguridad y confianza en vos mismo, entonces decile lo que te pasa... Si, ya sé que duele el amor, pero es que debemos aceptar, es algo por lo que todos pasamos, y así es la vida... 
c. Es preferible que la lastimes ahora con la verdad y no después que se de cuenta que estas por ella sólo por no lastimarla y que vea que sólo ha perdido el tiempo pudiendo darse la oportunidad con alguien más. no importa cuanto duela siempre se honesto eso a la larga es mejor que una mentira y después ella te lo agradecerá porque te recordara como alguien especial y no como alguien que la engaño y le hizo daño.

d. El hecho de terminar con alguien siempre va a hacer que uno o los dos queden lastimados, aqui el asunto es como se lo vas a decir, no llegues diciendoselo asi de golpe, porque va a pensar que si quieres con otra chica, mas bien platica un poco sobre la amistad, y poco a poco le vas diciendo que tal vez no estas muy seguro de querer continuar con ella y que lo mejor para los 2, es terminar, para que en un futuro no surjan nuevos problemas y mas enredosos y dificiles de solucionar. Suerte, y recuerda dicelo CON MUCHO TACTO

\subsubsection{Tipos de consejos}

Martínez Flor (2005) analiza los consejos en interacciones cara a cara y propone que estos pueden dividirse en tres categorías de acuerdo con las estrategias que se usen: 1) directas, 2) (indirectas) convencionalizadas y 3 ) indirectas (no convencionalizadas). Las estrategias directas indican clara e inequívocamente lo que sugieren los consejeros. En las estrategias convencionalizadas el enunciado no es tan directo como en el primer tipo, pero igualmente se entiende como un consejo debido a una interpretación estándar de su fuerza ilocucionaria. Las estrategias indirectas no expresan las intenciones del hablante ni usan estructuras idiomáticas o convencionales, y, por ende, el receptor debe inferir la intención del hablante. Las estrategias, con ejemplos del corpus de consejos en línea, se presentan en la siguiente tabla adaptada de Martínez Flor (2005:175).

Tabla 1: Categorías de estrategias lingüísticas, subcategorías y ejemplos de consejos

\begin{tabular}{|c|c|c|}
\hline $\begin{array}{l}\text { Categorías globales de } \\
\text { consejos }\end{array}$ & Subcategorías & Ejemplos \\
\hline 1. Directas & $\begin{array}{l}\text { Directiva } \\
\text { Directiva mitigada } \\
\text { Verbo performativo } \\
\text { Declarativa } \\
\text { Declarativa mitigada } \\
\text { Sustantivo }\end{array}$ & $\begin{array}{l}\text { Dale tiempo/ No juegues con ella } \\
\text { Deberías dejar esa relación hasta ahí!! } \\
\text { yo te aconsejo que hables con ella sobre } \\
\text { su relacion } \\
\text { Yo te digo q y cortar por lo sano. } \\
\text { Pienso que el seguir con ella seria mas } \\
\text { danino que decirlela verdad } \\
\text { Mi consejo es que hables con ella. }\end{array}$ \\
\hline 2. Convencionalizadas & $\begin{array}{l}\text { Preguntas } \\
\text { Expresiones } \\
\text { impersonales } \\
\text { Expresiones } \\
\text { condicionales }\end{array}$ & $\begin{array}{l}\text { Por q no hablas con la familia y listo } \\
\text { hay que actuar con un poco de frialdad } \\
\text { En tu lugar, yo cortaría la relación } \\
\text { inmediatamente }\end{array}$ \\
\hline
\end{tabular}




\begin{tabular}{|l|l|l|}
\hline 3. Indirectas & $\begin{array}{l}\text { Declaraciones } \\
\text { generales }\end{array}$ & $\begin{array}{l}\text { Es mas facil dejar una relacion en el } \\
\text { menor tiempo posible }\end{array}$ \\
$\begin{array}{l}\text { Experiencias } \\
\text { personales }\end{array}$ & $\begin{array}{l}\text { flaco a mi me pasa exactamente lo } \\
\text { mismo que vos }\end{array}$ \\
\hline
\end{tabular}

Como puede apreciarse, hay una amplia diversidad sintáctica en la formulación de consejos, especialmente en la producción de estrategias directas. El hallazgo más significativo en el corpus analizado, sin embargo, fue la alta frecuencia de directivas, típicamente asociadas con el modo imperativo, y la baja frecuencia en el uso de las estrategias directas restantes. Si bien los consejeros también produjeron estrategias convencionalizadas e indirectas no convencionalizadas, estas se usaron para formular elaboraciones y evaluaciones enmarcando consejos directos. Muy pocas de estas estrategias fueron empleadas para dar consejos propiamente dichos.

Dada la predilección por el uso de directivas que revelan los datos, cabe preguntarse entonces si los participantes en estos foros son descorteses, o simplemente responden al carácter informal de la comunicación en línea. Lo que es notable en el corpus es la amplia gama de estrategias de atenuación (v. cap. 12) que usan los consejeros para mitigar/suavizar las directivas por medio de modalizadores, expresiones de empatía, uso de vocativos, cumplidos, expresiones de afecto y aliento, y el empleo de emoticonos. Las elaboraciones y asesoramientos que típicamente enmarcan los consejos directos también funcionan como procedimientos de atenuación. Briz (2002) sugiere que, en las conversaciones coloquiales en español, la atenuación se usa como un recurso estratégico para buscar la aceptación del oyente, y, por lo tanto, se relaciona con el establecimiento de la imagen social. La cortesía, por consiguiente, no es un fin en sí mismo sino un medio para un fin. En el caso de los consejos, este fin es mitigar la amenaza potencial del consejo ofrecido y hacerlo más aceptable para el receptor.

Por otra parte, en los consejos en línea, el uso de imperativos podría tener otra interpretación, relacionada con factores contextuales, en este caso, el medio de comunicación. Como ya hemos mencionado, el lenguaje utilizado en Internet tiende a ser breve, conciso, sintácticamente simple y directo. Puede ser que, en situaciones en las que quien busca y quien da consejos no se conocen, las consideraciones de jerarquía sean irrelevantes. Si bien quien imparte un consejo puede asumir el rol de experto, el anonimato de los participantes y la falta de continuidad en la interacción implican que quien solicita consejos no está obligado a aceptar el consejo ofrecido, y, por lo tanto, los problemas de imagen social desempeñan un papel menor (o tal vez ninguno). Quizás la falta de continuidad en la interacción, y la imposibilidad de que el receptor del consejo pueda pedir aclaraciones conlleva otros principios pragmáticos, relacionados con la relevancia, la claridad y la economía del mensaje.

Actividad 2: Consejos asimétricos. Hemos mencionado que los consejos entre pares conllevan características que los distinguen de los consejos asimétricos, impartidos por expertos. Visita sitios web de consejos profesionales (por ejemplo, Cuidate, dedicado a la salud, o Todoexpertos, dedicado a temas muy variados). Examina las estrategias discursivas que se emplean en estos sitios: ¿Qué estrategia(s) se emplea(n) con más frecuencia? Compáralas con los ejemplos de la Actividad 1. ¿Cuáles son las similitudes y diferencias en el uso que observas? ¿Hay ciertas categorías ausentes en un área, pero presentes en otra? ¿O es solo una cuestión de frecuencia? 
Actividad 3: Influencia del medio de interacción. Compara la formulación de los consejos en la Actividad 1 con consejos impartidos en periódicos y revistas. ¿Qué elementos encuentras en los consejos en foros en línea que los diferencian de los consejos publicados en la prensa?

\section{Preguntas para la reflexión}

- ¿Cuáles son las ventajas e inconvenientes de utilizar sitios web de preguntas y respuestas en línea en la investigación pragmática?

- ¿Utilizas frecuentemente sitios web de preguntas y respuestas? ¿Los encuentras útiles? ¿Por qué/por qué no?

- ¿Qué importancia tienen los emoticonos y emojis en la formulación de consejos? ¿Piensas que son siempre expresiones de empatía? ¿O pueden tener otras funciones? (v. cap. 13)

- ¿Piensas que el estudio de los consejos en línea puede tener aplicaciones prácticas? ¿Puedes identificar algunas?

Posibles temas para un ensayo o proyecto del curso

- ¿Qué importancia tiene el género en la formulación de consejos? Examina algunos sitios web que imparten consejos sentimentales y compara los consejos impartidos por hombres y mujeres a hombres y mujeres, tomando en cuenta solo los consejos en los que es posible determinar el género de consejeros y destinatarios. Si encuentras diferencias, ¿en qué consisten? ¿se relacionan con la forma o el contenido de los consejos? ¿con el género del que pide consejo, o del que lo ofrece?

- Muchos investigadores han observado diferencias interculturales en la formulación de los consejos. Selecciona sitios web de preguntas y respuestas en otro(s) idioma(s) que hables/leas y compáralos con sitios similares en español. ¿Qué podemos aprender de este tipo de estudio? Compara sitios web de distintos países de cultura hispánica y estudia las diferencias regionales si las hubiera.

En el capítulo de metodología (Cap. 22) encontrarás herramientas que facilitarán la formulación de tu estudio.

- Otros: Añade uno o dos posibles temas relacionados con los consejos que te parezcan interesantes:

\section{Lecturas recomendadas}

Briz, A. (2003). La estrategia atenuadora en la conversación cotidiana española. En: Bravo, D. (ed.), Actas del Primer Coloquio Edice. La perspectiva no etnocentrista de la cortesía: Identidad sociocultural de las comunidades hispanohablantes, Universidad de Estocolmo, libro-e. 17-46

Haverkate, H. (1994). La cortesía verbal: estudio pragmalingüístico. Madrid: Gredos. Herring, S. y Androutsopoulos, J. (2015). Computer-mediated discourse 2.0. En: D. Tannen, H. E. Hamilton y D. Schiffrin, eds., The handbook of discourse analysis, 2nd ed., Malden, MA: Wiley-Blackwell, 127-151.

Locher, M. A. (2006). Advice online: Advice-giving in an American Internet health column. Amsterdam: John Benjamins. [Caps. 5 y 6] 
Martínez Flor, A. (2005). A theoretical review of the speech act of suggesting: Towards a taxonomy for its use in FLT. Revista Alicantina de Estudios Ingleses 18, 167-187.

Yus, F. (2010). Ciberpragmática 2.0: nuevos usos del lenguaje en Internet. Barcelona: Planeta. [Cap. 5]

\section{Lecturas complementarias}

Pudlinski, C. (2005). Doing empathy and sympathy: caring responses to troubles tellings on a peer support line, Discourse Studies, 7(3), 267-288.

Searle, J. R. (1976). A classification of illocutionary acts. Language in Society, 5, 1-23.

\section{Sobre consejos específicamente:}

Eisenchlas, S.A. (2012). Gendered discursive practices online, Journal of Pragmatics, 44, 335-45.

Limberg, H. y Locher, M. A., eds. (2012). Advice in discourse. Amsterdam: John Benjamins. [Caps. 12 y 13]

Morrow, P.R. (2006). Telling about problems and giving advice in an Internet discussion forum: Some discourse features. Discourse Studies, 8(4), 531-548.

Morrow, P. R. (2017). Requesting and advice-giving. En: C. R. Hoffmann y W. Bublitz,eds., Pragmatics of social media [Handbook of Pragmatics 11]. Berlin: De Gruyter, 661-690.

Placencia, M. E. (2010). Yahoo! Respuestas como columna de consejos: algunos rasgos de un género híbrido. Tonos Digital - Revista de Estudios Filológicos, 20. Disponible en: $<$ http://www.tonosdigital.es/ojs/index.php/tonos/article/view/601> 